\title{
Environmental and Familial Risk Factors of Parkinsons Disease: Case-Control Study
}

\author{
Jaya Sanyal, D.P. Chakraborty, Biswanath Sarkar, Tapas Kumar Banerjee, \\ Subhash Chandra Mukherjee, Bidhan Chandra Ray, V.R. Rao
}

\begin{abstract}
Background: While the cause of Parkinson's disease (PD) remains unknown, evidence suggests certain environmental factors, such as well water drinking, herbicides, pesticides exposure and neurotoxins, may trigger the chain of oxidative reactions culminating in the death of dopaminergic neurons in substantia nigra to cause Parkinsonism. To investigate the possible impact of environmental risk factors for idiopathic PD, a case-control study was performed in the Eastern India. Methods: During the period from January 1st, 2006 and December 10th, 2009, 175 PD patients (140 men, 35 women) and 350 non-Parkinson age-sex matched controls were included in the study. Subjects were given a structured neurological examination and completed an administered questionnaire which elicited detailed information on demographic data, pesticides, herbicides family history, occupation, dietary and smoking habits. Results: The multivariate analysis revealed that family history of PD, pesticide exposure, exposure to toxins other than pesticides and herbicides, rural living and previous history of depression were associated with increased risk of PD, whereas, smoking appeared to be a protective factor. Well water drinking for at least five years, though a significant risk factor on univariate analysis $(\mathrm{OR}=4.5$, $95 \%$ $\mathrm{CI}=2.1-9.9)$, could not be proved significant in multivariate analysis. Head trauma, vegetarian dietary habit, occupation involving physical exertion and exposure to domestic pets were not as significant risk factors. Conclusion: Results of our study support the hypothesis of multifactorial etiology of PD with environmental factors acting on a genetically susceptible host.
\end{abstract}

RÉSUMÉ: Facteurs de risque environnementaux et familiaux de la maladie de Parkinson : étude cas-témoin. Contexte : Bien que la cause de la maladie de Parkinson (MP) demeure inconnue, certains facteurs environnementaux comme la consommation d'eau de puits et l'exposition à des herbicides, à des pesticides et à des neurotoxines pourraient contribuer au déclenchement de la chaîne de réactions oxydatives menant à la mort des neurones dopaminergiques dans le locus niger et causer le parkinsonisme. Pour étudier l'impact possible de facteurs de risque environnementaux dans la MP idiopathique, une étude cas-témoin a été effectuée en Inde orientale. Méthodes : Du 1er janvier 2006 au 10 décembre 2009 , 175 patients atteints de la MP (140 hommes et 35 femmes) et 350 témoins non atteints de la MP, appariés pour l'âge et le sexe, ont été inclus dans l'étude. Les sujets ont subi un examen neurologique structuré et ont rempli un questionnaire sur les données démographiques, l'exposition à des pesticides et à des herbicides, l'histoire familiale, le métier ou la profession, les habitudes alimentaires et le tabagisme. Résultats : L'analyse multivariée a montré que l'histoire familiale de MP, l'exposition à des pesticides, l'exposition à des toxines autres que des pesticides et des herbicides, la vie à la campagne et l'histoire antérieure de dépression étaient associées à un risque accru de MP. Le tabagisme semblait être un facteur de protection. Bien que la consommation d'eau de puits pendant au moins 5 ans ait été un facteur de risque significatif à l'analyse univariée (RC = 4,5; IC à 95\% 2,1 à 9,9), ce n'était pas significatif à l'analyse multivariée. Le traumatisme crânien, le végétarisme, un métier comportant des efforts physiques et l'exposition à des animaux de compagnie n'étaient pas des facteurs de risque significatifs. Conclusion : Les résultats de notre étude sont en faveur de l'hypothèse d'une étiologie multifactorielle de la MP, des facteurs environnementaux agissant chez un individu génétiquement sensible à la maladie.

Can. J. Neurol. Sci. 2010; 37: 637-642

Parkinson's disease (PD), a neurodegenerative disease, affects approximately $1 \%$ of the elderly population over 60 years. Prevalence of PD varies between 18 and 148 per $1,00,000$ population world-wide ${ }^{1}$. Age-adjustment and restriction to studies using similar methodology reduce the variation between 102 and 190 per 1,00,000 population in Western countries. The Euro-Parkinson study ${ }^{2}$ reported the prevalence rates from five European countries namely USA, Germany, France, UK and Sweden within a similar range. As the world population ages, it is estimated that the cost of PD will continue to rise. Since its description by James Parkinson in 1817, many attempts have been made to elucidate its etiology although genetic susceptibility and environmental factors combined with the

From the Anthropological Survey of India (JS, BS, VRR), Jawaharlal Nehru Road; Department of Neurology (DPC), Bankura Medical College and Hospital; Department of Neurology (TKB), National Neuroscience Center; Department of Neurology (SCM), Calcutta Medical College and Hospital; Department of Chemistry (BCR), Jadavpur University, Kolkata, India.

Received January 5, 2010. Final Revisions Submitted April 8, 2010. Correspondence to: V.R. Rao, Anthropological Survey of India, 27 Jawaharlal Nehru Road, Spirit Building, Kolkata-700 016, India. 
effects of ageing seem to play a major role. Discovery of 1methyl, 4-Phenyl,1,2,3,6 tetrahydropyridine (MPTP)-induced parkinsonism generated great enthusiasm for search of environmental risk factors in the pathogenesis of PD. The most widely accepted hypothesis is an ecogenetic one, bringing into play genetic and environmental factors. Data from door-to-door surveys in different parts of India however showed a lower prevalence rate of PD in Indians compared to their Western counterparts. A crude prevalence rate of PD was reported to be 14.1 per $1,00,000$ in rural Kashmir in North India, 27 per $1,00,000$ population in Bangalore, South India and 16.1 per $1,00,000$ in rural Bengal, Eastern India ${ }^{3}$. The contribution of each factor needs to be determined to understand the epidemiology of this disease.

Attempts to study risk factors of PD are riddled with problems like absence of any biological marker, manifestation in older age and relative rarity of the disease. Most epidemiologists resort to case control studies. A case-control study was undertaken in Calcutta Medical College and Hospital (CMC) and National Neuroscience Centre (NNC), Kolkata to investigate the influence of various environmental and familial risk factors of Parkinson's disease in Eastern India. Only one such study in North India so far has been reported to our knowledge by M. Behari et al, 20014.

\section{Materials And Methods}

\section{Subjects}

The population social structure and cultural traits make the population a unique result of interactions between multiple biological, environmental, and behavioral forces. The present study included 175 PD patients attending the Movement Disorders Clinic (MDC) and Neuromedicine Out Patient Department (OPD) of CMC and NNC, Kolkata, a referral Center for neurological patients in Eastern India, an agriculturedependent region with small and medium sized factories. Hospitals like CMC and NNC are the main referral centers for cases related to movement disorders and are situated in the heart of Kolkata city, West Bengal. Patients of various economic, social and occupational backgrounds visit these hospitals. Diagnosis of PD was based on the following criteria: presence of at least three out of bradykinesia, rigidity, rest tremor and impaired postural reflexes. The Unified Parkinson's Disease Scale $^{5}$ was performed for each patient to estimate the disease severity. Inclusion criteria were (i) disease duration of at least one year, (ii) good and persistent response to L-dopa.

Exclusion criteria for the present study were (i) features suggestive of atypical Parkinsonism e.g. early falls, symmetric onset of disease symptoms, axial rigidity greater than limb rigidity, early cognitive decline, lack of or early warning of Ldopa response, early autonomic features, vertical gaze impairment; drug induced parkinsonism and vascular or metabolic causes of parkinsonism. Known causes for secondary parkinsonism, such as Wilson's disease, intoxication $\left(\mathrm{CO}, \mathrm{CS}_{2}\right.$, $\mathrm{Mn})$, Sewaga's disease, encephalitis, pallidopyramidal disease, or Hallervorden-Spatz disease, were excluded after a review of clinical and laboratory information.

Non-Parkinson two elderly controls for each case matched by age ( \pm 3 years) and sex were selected from apparently healthy relatives of patients attending neuromedicine OPD and MDC of
CMC and NNC. As these controls subjects were residents of the same community or adjacent suburb, their socio-demographic characteristics were expected to be similar to those of the patient group. Total number of controls was 350. All the subjects underwent a comprehensive clinical, physical and neurological examination to confirm the diagnosis or exclude the presence of major neurological disease and cases were graded by the Hoehn and Yahr stages ${ }^{6}$. The nature and purpose of the study were explained to all of them. A written informed consent was obtained by specialists from each case and control before the interview began.

The study protocol was approved by the Ethics Committee of the Anthropological Survey of India and collaborating hospitals.

\section{Data Collection}

Cases and controls were drawn from a population base consisting of all individuals residing in West Bengal for at least three generations. The individuals recruited in this study are members of various age and socio-economic groups who had visited the clinic between January 1st, 2006 and December 10th, 2009. Two hundred patients were registered in our Movement Disorder data bank. Seven patients died and 18 moved out of the study area since the time of initial ascertainment. Finally, 175 potential cases were recruited and met the eligibility criteria for the present study. Potential subjects were sent a recruitment letter inviting them to participate in the study. Phone contact by trained interviewer was initiated within two weeks after the recruitment letter was sent. Both subjects were interviewed; they were given the Mini Mental State Examination to screen for cognitive impairment. A cut off score of less than 24 was chosen. Participants were given an open-ended structured intervieweradministrative risk factor questionnaire which was used to collect information from cases and controls in a face-to-face interview and each case and control was examined clinically by a neurologist face-to-face. Each interview and examination took about 40-45 minutes. All the 525 subjects actively took part in this study and their high response helped it to reach a $100 \%$ participation rate. Both subjects and accompanying family members were allowed to answer. Follow-up visits at home took place after two years. Before the questionnaire was formally administered, content validity was examined by a panel consisting of neurologists, epidemiologists and a biostatistician. Information from subjects was obtained regarding the following: (i) Demographic data: name, address, age, sex, educational status, monthly income, occupation/professional status of subject during his/her life time, residence area (rural/urban), environment status of the house (close to a factory and the type of factory); (ii) environmental factors: diet (vegetarian/nonvegetarian), type of vegetable consumption(raw/cooked), source of drinking water (consumption of well water or in association with other water), exposure to insecticides, herbicides, rodenticides, other toxic chemicals, length of stay on a farm, pets at home (for at least five years), smoking and alcohol intake; (iii) History of depression (according to DSM IV-TR criteria) preceding this illness, (iv) past history of head trauma, major illness (including infections); (v) family history of PD, dystonia and essential tremor in first and second degree relatives. Occupations of subjects were classified into manual laborers, farmers, housewives, those having contact/exposure to toxic 
chemicals (laboratory chemicals, organic solvents, chemical fertilizers, farming chemicals, heavy metals) and others (officials, executives, clerks, businessman, etc). A subject was considered a rural resident if he had lived in the village for at least ten years.

Well water drinking was considered positive if a subject drunk exclusively well water continuously for at least five years. Dietary habits were grouped into two major categories-vegetarian and non-vegetarian. Alcohol consumption (type and quantity) was considered positive if the subject consumed alcohol at least $30 \mathrm{ml} /$ day on average for at least five years. Smoking was considered positive if the subject smoked at least five cigarettes per day for five years (active smokers).

Questions on pesticide names were asked in the pilot studies. The likelihood and the level of exposure were assessed in reference to the jobs by a panel of two experts in occupational health hygiene and in agricultural risk prevention. The expertise took into account the size of the farms, the frequency of applying pesticides themselves with less modern equipment. It is believed that they experience higher exposure. Exposure to insecticides, herbicides and rodenticides for at least five years was considered positive. People exposed to toxic chemicals occupationally e.g. laboratory chemicals, heavy metals, farming chemicals, chemical fertilizers were also grouped as exposed to toxins other than pesticides and herbicides. Family trees were drawn up to three generations including first and second degree relatives and occurrence of PD, Dystonia and essential tremor was enquired into.

\section{Statistical Methods}

Data entered were cross checked for errors and corrected if necessary. Chi-square test was used to assess the association between PD and various risk factors separately. Matched unadjusted odds ratio (OR) and their corresponding 95\% confidence interval (CI) were calculated for each of the potential risk factors in SPSS v11.5. Risk factors showing significance in univariate analysis were subjected to multivariate analysis. In this study, $p$ value smaller than 0.05 was considered statistically significant.

\section{Results}

There were 175 cases (Males $[\mathrm{M}]=140$; Females $[\mathrm{F}]=35)$ and 350 age ( \pm 3 years) and sex matched controls. Mean $( \pm$ SD) age of cases was $55.19( \pm 10.17$ years) ranges from $27-80$ years and for controls this was 55.03 ( \pm 10.13 years $)$ and ranged from $28-80$ years respectively. The risk factors associated with the PD in the present samples are shown in Tables 1 and 2 .

Occupation, educational status, dietary habits and exposure to rodenticides and herbicides, were not associated with occurrence of PD. Smoking had an inverse association with PD. Smoking for least five years had significant protective effects $(\mathrm{OR}=0.045$,

Table 1: Environmental risk factors and their association with PD

\begin{tabular}{|c|c|c|c|c|c|}
\hline \multirow[t]{2}{*}{ FACTORS } & \multicolumn{2}{|l|}{ CASE (n=175) } & \multicolumn{2}{|c|}{ CONTROL $(n=350)$} & \multirow[t]{2}{*}{ p value } \\
\hline & YES & NO & YES & NO & \\
\hline \multicolumn{6}{|l|}{ 1. Occupation } \\
\hline a) Manual Labour & $19(10.85 \%)$ & $156(89.14 \%)$ & $10(2.85 \%)$ & $340(97.14 \%)$ & $<0.05$ \\
\hline b) House wife & $25(14.28 \%)$ & $150(85.71 \%)$ & $58(16.57 \%)$ & $292(83.42 \%)$ & $>0.05$ \\
\hline c) Farmer & $2(1.14 \%)$ & $173(98.85 \%)$ & $2(0.57 \%)$ & $348(99.42 \%)$ & $>0.05$ \\
\hline $\begin{array}{l}\text { 2. Exposed to toxins } \\
\text { other than pesticides }\end{array}$ & $39(22.28 \%)$ & $136(77.71 \%)$ & $7(2 \%)$ & $343(98 \%)$ & $<0.01^{*}$ \\
\hline \multicolumn{6}{|l|}{ 3. Educational status } \\
\hline a) Illiterate & $7(4 \%)$ & $168(96 \%)$ & $9(2.57 \%)$ & $341(97.42 \%)$ & $>0.05$ \\
\hline b) Literate & $134(76.57 \%)$ & $41(23.42 \%)$ & $325(92.85 \%)$ & $25(7.14 \%)$ & $>0.05$ \\
\hline c) Professional & $34(19.42 \%)$ & $141(80.57 \%)$ & $16(4.57 \%)$ & $334(95.42 \%)$ & $>0.05$ \\
\hline \multicolumn{6}{|l|}{ 4. Diet } \\
\hline a) Non-vegetarian & $174(99.42 \%)$ & $1(0.57 \%)$ & $347(99.14 \%)$ & $3(0.85 \%)$ & $>0.05$ \\
\hline b) Vegetarian & $1(0.57 \%)$ & $174(99.42 \%)$ & $3(0.85 \%)$ & $347(99.14 \%)$ & $>0.05$ \\
\hline 5. Well water & $23(13.14 \%)$ & $152(86.85 \%)$ & $10(2.85 \%)$ & $340(97.14 \%)$ & $<0.05$ \\
\hline 6. Rural living & $95(54.28 \%)$ & $80(45.71 \%)$ & $60(17.14 \%)$ & $290(82.85 \%)$ & $<0.01^{*}$ \\
\hline 7. Pets & $27(15.42 \%)$ & $148(84.57 \%)$ & $34(9.71 \%)$ & $316(90.28 \%)$ & $>0.05$ \\
\hline 8. Smoking & $32(18.28 \%)$ & $143(81.71 \%)$ & $123(35.14 \%)$ & $227(64.85 \%)$ & $<0.01^{*}$ \\
\hline 9. Alcohol & $14(8 \%)$ & $161(92 \%)$ & $12(3.42 \%)$ & $338(96.57 \%)$ & $>0.05$ \\
\hline 10. Pesticides & $47(26.85 \%)$ & $128(73.14 \%)$ & $4(1.14 \%)$ & $346(98.85 \%)$ & $<0.01^{*}$ \\
\hline 11. Herbicides & $6(3.42 \%)$ & $169(96.57 \%)$ & $4(1.14 \%)$ & $346(98.85 \%)$ & $>0.05$ \\
\hline 12. Rodenticides & $2(1.14 \%)$ & $173(98.85 \%)$ & $2(0.57 \%)$ & $348(99.42 \%)$ & $>0.05$ \\
\hline 13.Previous depression & $67(38.28 \%)$ & $108(61.71 \%)$ & $56(16 \%)$ & $294(84 \%)$ & $<0.05^{*}$ \\
\hline 14. Family history of PD & $19(10.85 \%)$ & $156(89.14 \%)$ & $1(0.28 \%)$ & $343(98 \%)$ & $<0.01^{*}$ \\
\hline 15. Head trauma & $27(15.42 \%)$ & $148(84.57 \%)$ & $25(7.14 \%)$ & $325(92.85 \%)$ & $>0.05$ \\
\hline
\end{tabular}

* statistical significance 
95\% CI=0.26-0.79). Alcohol and tea consumption did not have any statistically significant relation to occurrence of PD. Well water drinking for at least five years, though a significant risk factor on univariate analysis $(\mathrm{OR}=4.5,95 \% \mathrm{CI}=2.1-9.9)$, could not be proved significant in multivariate analysis. Head trauma and domestic pets also didn't come as significant risk factors.

After multivariate analysis, factors found to be positively correlated with PD were family history of PD in first and second degree relative $(\mathrm{OR}=21.4,95 \% \mathrm{CI}=6.36-70.12)$, exposure to pesticides $(\mathrm{OR}=17.12,95 \% \mathrm{CI}=4.97-58.84)$, exposure to toxins other than pesticides, herbicides $(\mathrm{OR}=7.54,95 \% \mathrm{CI}=2.72$ 20.89), rural living ( $\mathrm{OR}=4.05,95 \% \mathrm{CI}=2.53-6.49)$, prior depression $(\mathrm{OR}=1.98,95 \% \mathrm{CI}=1.18-3.29)$. Smoking was negatively correlated $(\mathrm{OR}=0.45,95 \% \mathrm{CI}=0.26-0.79)$ (Table 2$)$.

\section{DisCUSSION}

Our study revealed that family history of Parkinson's disease, pesticide exposure, exposure to toxins other than pesticides, rural living and previous history of depression were associated with increased risk of PD and smoking is inversely associated (Table 2).

Mean age $( \pm$ SD) of cases $(55.19 \pm 10.7$ years $)$ and mean age of onset of symptoms $(52.08 \pm 11.16$ years $)$ in our study group is comparable to the other case-control study available in India ${ }^{4}$ highlighting the similarity in natural history of Parkinson's disease in two different parts of the country. This could be explained by (a) the lower life expectancy on the Indian subcontinent, (b) older patients with advanced disease may prefer to stay at home due to increased disability, better family support system in India, poor transport facilities and belief in alternative system of medicine in advanced disease in the face of poor response to allopathic medicines. However, the mean age of patient populations was comparatively less in other studies ${ }^{7}$.

Comparable to the other study in India ${ }^{4}$, our study also showed an excess of males among PD patients, male:female ratio being $4: 1$. The average standardized prevalence ratio is $3.5: 1$; for incidence studies the ratio is $3.4: 1^{1}$, The present study being a hospital based study, may reflect a higher male-female ratio as more males seek medical attention for comparably severe medical illness in Indian context. Such hospital-based studies are generally misleading as survival of women recruited from hospital is worse as compared to men. This suggests a bias in favor of males in seeking medical advice for neurological disorders.

Our observation and several others have found the importance of family history to be a significant risk factor ${ }^{8-11}$ whereas some other studies have failed to show association with $\mathrm{PD}^{12}$. Our study shows a higher odds ratio when compared to a similar study from North India ${ }^{4}$. This may reflect (i) Genetic variability in our study population, (ii) Presence of some environmental factors causing familial clustering of cases (iii) Any protective factor in diet on environment in other study populations. In the background of discovery of a number of genes responsible for PD, studies exploring the role of molecular pathogenesis are initiated in India. Frequency of PARKIN gene mutations in Eastern India showed $7.24 \%{ }^{13}$ and $0.125 \%$ related to Leucine rich repeat kinase 2 (LRRK2) gene mutations in North India ${ }^{14}$. Family history positive for PD was found in $10.9 \%$ cases in the present study.
Table 2: Significant risk factors associated with Parkinson's disease obtained from multivariate analysis

\begin{tabular}{l|l|l}
\hline VARIABLES & $\begin{array}{l}\text { ODDS } \\
\text { RATIO }\end{array}$ & $\begin{array}{l}\text { 95\% } \\
\text { CONFIDENCE } \\
\text { INTERVAL }\end{array}$ \\
\hline 1. Family history of PD & 21.4 & $6.36-70.12$ \\
\hline 2. Pesticide exposure & 17.12 & $4.97-58.84$ \\
\hline 3. Rural living & 4.05 & $2.53-6.49$ \\
\hline 4. Previous history of depression & 1.98 & $1.18-5.29$ \\
\hline 5. Toxins other than pesticide & 7.54 & $2.72-20.89$ \\
\hline 6. Smoking & 0.45 & $0.26-0.79$ \\
\hline
\end{tabular}

We found significant association between PD and pesticide exposure which is at par with the other studies from around the world ${ }^{15-21}$. Pesticides and other chemical agents have attracted the attention of investigators as a risk factor of PD because MPTP may cause many cases of secondary Parkinsonism and is structurally similar to Paraquet, a herbicide. Some clinical reports have also indicated the association between PD and use of herbicides and pesticides ${ }^{22,23}$. However, some case-control studies found no clear association between them ${ }^{24-28}$, similar to the result of the study of North India ${ }^{14}$. The discrepancy between the two studies in the two parts of the same country can be explained by methodological variation. Factors like rural living, farming and use of pesticides and insecticides appear to be interrelated. Most studies that show increased risk of PD with pesticides exposure also show increased risk with rural living. But in the study from Northern part of our country ${ }^{4}$, both cases and controls were collected from the same catchment area of the hospital and this may be one of the explanations why rural living could not emerge as a risk factor. In our study, controls included relatives of patients accompanying them in our clinic and OPD which included both rural and urban subjects in a more random fashion. This is probably why both pesticides exposure and rural living emerged as significant factor.

In a clinic based study like ours, it was difficult to ascertain the nature of pesticides but mostly they were of organophosphorus, organochlorine, carbamates in chemical nature. Quantification of exposure to pesticides was not possible in our study. Toxins and chemicals may act as a risk factor of PD by damaging mitochondrial enzymes, reduction of adenosine triphosphate (ATP) formation, and formation of free radicals in varying combinations as in the MPTP-animal model. Our study revealed exposure to toxins like laboratory chemicals, heavy metals, chemical fertilizers and tanning chemicals as a significant risk factor. Previous studies highlighted the importance of exposure to industrial chemicals ${ }^{27,29}$ and occupational exposure to copper, lead and iron as risk factors of PD in those with a positive family history ${ }^{30}$ which points towards a genetic environmental interaction. However, there are studies which didn't show such an association ${ }^{31,32}$. Manganese contained in several dithio-carbamates (manel) has been shown to produce 
clinical signs similar to $\mathrm{PD}^{33}$. Variation in the result of studies regarding pesticides and other toxic chemicals may be explained due to methodological differences, differences in quantity of exposure or genetic variability of the population studied.

Rural living was a statistically significant risk factor of PD in the present study which is very much in accordance with the earlier findings $1^{17,25,28}$. However, this observation in not consistent with other studies $4,17,34,35$. Agriculture is the main occupation of rural people which is linked to pesticides exposure and also well water drinking. As indicated above, rural living did not prove to be a significant risk factor in the study from Northern India ${ }^{4}$ probably due to the fact that cases and controls were derived from the same catchment area. In our study, vegetarian and non-vegetarian dietary habit did not show any association with occurrence of PD.

Different epidemiological studies ${ }^{4,25,27,36}$ like ours, showed well water consumption exclusively for more than five years as a risk factor. It is proposed that well water could act as a carrier of a potential toxic agent or an infective agent.

Many patients with Parkinson's disease have clinically significant anxiety, depression, fatigue, sleep disturbance, or sensory symptoms. The comorbidity of these nonmotor symptoms and their relationship to PD severity has not been extensively evaluated. Our study revealed an association between PD and previous history of depression up to 15 years prior to PD symptom onset. Although, the relevance of depression in pathogenesis of PD is unclear, depression has found to be common in PD patients and predates symptoms of PD. This might be linked to a reduction in brain catecholamine, serotonin or dopamine.

Like many other studies $4,20,35,37,38$, the present study also showed significant negative correlation of PD with smoking whereas Behari et $\mathrm{al}^{4}$ showed smokers of greater than 20 years duration did not enjoy the protection from smoking probably due to increased mortality. Cigarette smoking may exert its protective effect through various means: (a) It contains monoamine oxidase-B (MAO-B) inhibitor activity ${ }^{39}$, MAO-B breaks down dopamine, releasing free radicals which in turn damages nigral cells $\mathrm{s}^{40}$ (b) Nicotine up regulates nicotinic receptors masking early symptoms of $\mathrm{PD}^{41}$. (c) $\mathrm{CO}$ from smoke reduces free radicals ${ }^{40}$. Although there are explanations for inverse relationship between PD and smoking, the issue is still unsettled.

As shown in other studies ${ }^{4,35}$, we did not find any association of PD with exposure to domestic pets for five years whereas, two times reduced risk for developing PD was found for those exposed more than ten years ${ }^{4}$. Whether there is any mechanism of possible protective effect of exposure to pets in PD is difficult to attribute to any factor and this field needs to be explored. In studies on survival of cardiac infarction, patients who owned dogs had better survival as compared to those who did not own a pet. It might be hypothesized that sympathetic nervous system arousal and decrease in anxiety in response to stressors could play a role in survival after cardiac infarction. This hypothesis may not be applicable in etiology of PD. Inflammatory processes and cytokine expression has been implicated in the pathogenesis of several neurodegenerative disorders. Inflammation is a common finding in the PD brain, but due to the limitation of postmortem analysis its relationship to disease progression cannot be established. However, studies using the MPTP model of PD have also identified inflammatory responses in the nigrostriatal pathway that precede neuronal degeneration in the $\mathrm{SNpc}^{42}$. Chronic microglia activation links proteinopathies to neurodegeneration; thus current and future use of antiinflammatory approaches can be implemented to protect vulnerable neuronal populations in PD.

The quantum of land owned by a rural household is perhaps an important indicator of the economic status of the household. In India, three different types of crops are cultivated in a year per field. The field size varies from 0.1-2 acres of land. Farmers use different pesticides to cultivate crops like Dhaan (rice), vegetables, potato, cabbage, brinjal etc. Ketazine ( $250 \mathrm{ml} / \mathrm{spray})$, Action 505, Eldrine, Phostathione, are some of the commonly used pesticides sprayed to eradicate pests. Though the cut off value for the use of pesticides has been kept to five years, it has been seen that patients exposed to such toxic substances from their younger years have more severe PD symptoms (Hoehn and Yahr score > 4) than those exposed at a later stage. Manual laborers though engaged in other occupation, sometimes also work in such open fields. This may be the reason that they have a greater risk for occurrence of PD. It was expected that farmers would comprise a significant proportion of cases but only two cases $(1.1 \%)$ and two controls $(0.5 \%)$ were farmers. The farmers in the PD cohort are of older age with one of them having a positive family history. Comparatively, the controls with farming as an occupation were of younger age. It can be assumed that with longer years of exposure to pesticides they might develop PD in their lifetime which explains the discrepancy that farming as an occupation was not associated with PD. In rural West Bengal, housewives of farmer families and also people of other professions like shop keepers and small businessman handle pesticides during cultivation of land seasonally. This indicates direct exposure to pesticides is probably more important than rural living or farming as a risk factor. Some studies favor farming as a risk factor of $\mathrm{PD}^{17,30,36,41}$. But some others tally with our finding $g^{4,25,31,35}$. It is hard to suggest any explanation for these results and further studies have to be awaited to find out whether there is a trule effect from some factor in these jobs or if these findings are of a chance character. The other factors which did not show any associations were tea, alcohol, diet, head trauma and level of physical activity.

Factors like well water drinking and occupations like manual laborers showed significant univariate OR $(3.39,95 \%$ CI=1.946.23 ), but no significance level was detected at multivariate analysis. So probably it acted as confounding factors with rural living and pesticide exposure.

There are certain limitations of the present study. Subjects were recruited from referral hospital populations, not from community based epidemiological surveys. Occupation, education and other socio-economic factors influence the likelihood and the timing of a case coming to medical attention. Similarly, family history of PD in relatives may have been biased as it was based on self-report and verification by clinical examination of affected family members was not possible in all the cases. Parkinsons disease patients being more aware of signs and symptoms of disease are likely to identify initial symptoms early and hence over-report. Some distortions and omissions are inevitable. Chance of recall bias is there as patients are more likely to recall past events than the controls. Some information 
like family history could not be verified as it was a clinic based survey.

\section{CONCLUSIONS}

The study supports the hypothesis of multifactorial etiology of PD with environmental factors acting on subjects with genetic predispositions resulting in damage to the dopaminergic nigral neurons.

\section{ACKNOWLEDGEMENT}

This research work is supported by the grant from Anthropological Survey of India, Ministry of Culture, Government of India. The authors thank the PD patients and control subjects for voluntarily taking part in this research work.

\section{REFERENCES}

1. Zhang ZK, Roman GC. Worldwide occurrence of parkinson's disease: an updated review. Neuroepidemiology. 1993;12: 195-208.

2. de Rijk MC, Launer LJ, Berger K, et al. Prevalence of parkinson's disease in Europe: a collaborative study of population-based cohorts neurologic diseases in the elderly research group. Neurology. 2000;54:S21-3.

3. Muthane UB, Ragothaman M, Gururaj G. Epidemiology of parkinson's disease and movement disorders in India: problems and possibilities. JAPI. 2007;55:719-24.

4. Behari M, Srivastava AK, Das RP, Pandey RM. Risk factors of Parkinson's disease in Indian patients. J Neurol Sci. 2001;190(12):49-55.

5. Fahn S, Elton RL, members of the UPDRS Development Committee. The Unified Parkinson's Disease Rating Scale. In: Fahn S, Marsden CD, Calne DB, Goldstein M, editors. Recent developments in Parkinson's Disease, Vol. II, Florham Park, NJ. Macmillan Health Care Information; 1987. p. 153-63.

6. Hoehn MM, Yahr MD. Parkinsonism: onset, progression, and mortality. Neurology. 1967;17:427-42.

7. De Michele G, Fill A, Volpe G, et al. Environmental and genetic factors in Parkinson's disease: a case-control study in southern Italy. Mov Disord. 1996;11(1):17-23.

8. Uitti RJ, Shinotoh M, Hayward M, et al. Familial Parkinson's disease: a case-control study of families. Can J Neurol Sci. 1997; 24:127- 32

9. Marder K, Tang MX, Mejia H, et al. Risk of Parkinson's disease among first-degree relatives: a community-based study. Neurology. 1996;47:155-60.

10. Elbaz A, Grigoletto F, Baldereschi M, et al. Familial aggregation of Parkinson's disease: a population-based case-control study in Europe: EuroParkinson study group. Neurology. 1999;52: 1876-82.

11. Tanner CM. The role of environmental toxins in the etiology of Parkinson's disease. Trends Neurosci. 1989;12:49-54.

12. Golbe LI. The genetics of Parkinson's disease: a reconsideration. Neurology. 1990;40:7-14.

13. Biswas A, Gupta A, Naiya T, et al. Molecular pathogenesis of Parkinson's disease: identification of mutations in the Parkin gene in Indian patients. Parkinsonism Relat Disord. 2006;12: 420-6.

14. Punia S, Behari M, Govindappa ST, et al. Absence/rarity of commonly reported LRRK2 mutations in Indian Parkinson's disease patients. Neurosci Lett. 2006:409;83-8.

15. Semchuk KM, Love EJ, Lee RG. Parkinson's disease: a test of the multifactorial etiologic hypothesis. Neurology. 1993;43: 1173-80.

16. Ho Sc, Woo J, Lee CM. Epidemiologic study of Parkinson's disease in Honkong. Neurology. 1989;39:1314-18.

17. Golbe LI, Farell TM, Davis PH. Follow-up study of early-life protective and risk factors in Parkinson's disease. Mov Disord. 1990;5:66-70.
18. Vanacore N, Nappo A, Gentile M, et al. Evaluation of risk of Parkinson's disease in a cohort of licensed pesticide users. Neurol Sci. 2002;23:S119-20.

19. Fall PA, Fredrikson M, Axelson O, el al. Nutritional and occupational factors influencing the risk of Parkinson's disease: a case-control study in Southeastern Sweden. Mov Disord. 1999;14:28-37.

20. Rajput AH, Uitti R, Stern W, et al. Geography, drinking water chemistry, pesticides and herbicides and the etiology of Parkinson's disease. Can J Neurol Sci. 1987:14:414-18.

21. Baldi I, Cantagrel A, Lebailly P, et al. Association between Parkinson's disease and exposure to pesticides in Southwestern France. Neuroepidemiology. 2003;22:305-10.

22. Sanchez-Ramos J, Hefti F, Weiner W. Paraquat and Parkinson's disease. Neurology. 1987;37:728.

23. Sechi GP, Agnetti V, Piredda M, et al. Acute and persistent parkinsonism after use of diquat. Neurology. 1992;42:261-3.

24. Koller W, Veter-Overfield B, Gray C. Environmental risk factors in Parkinson's disease. Neurology. 1990;40:1218-21.

25. Rocca WA, Anderson DW, Meneghini F, et al. Occupation, education and Parkinson's disease: a case-control study in an Italian population. Mov Disord. 1996;11:201-6.

26. Jimenez-Jimenez FJ, Mateo D, Gimenez Roldan S. Exposure to well water and pesticides in Parkinson's disease: a case-control study in the Madrid area. Mov Disord. 1992;7:149-52.

27. Morano A, Jimenez-Jimenez FJ, Molina JA, Antolin MA. Risk, factors for Parkinson's disease: case-control study in the province of Caceres, Spain. Acta Neurol Scand. 1994;89:164-70.

28. Taylor C, Saint Hilaire M, Cupples L, et al. Environmental, medical, and family history, risk factors for Parkinson's disease: a New England based case control study. Am J Med Genet. 1999; 88:742-9.

29. Hertzman C, Wiens M, Bowering D, Snow B. Parkinson's disease case control study of occupational and environmental risk factors. Am J Int Med. 1990;17:349-55.

30. Rybicki BA, Johnson CC, Peterson EL, et al. A family history of Parkinson's disease and its effects on other PD Risk factors. Neuroepidemiology. 1999;18:270-8.

31. Preux PM, Condet A, Anglade C. Parkinson's disease and environmental factors. Neuroepidemiology. 2000;19:333-7.

32. Bharucha NE, Bharucha EP, Bharucha SE, et al. Prevalence of Parkinson's disease in the Parsi Community of Bombay, India. Arch Neurol. 1988;45(12):1321-3.

33. Meco G, Bonifati V, Vanacore V, Fabrizio E. Parkinsonism after chronic exposure to the fungicide, maneb (manganese ethylenebis-dithiocarbamate). Scand J Work Environ Health. 1994;20(4): 301-5.

34. Kuopio AM, Marttila RJ. Helenius H, et al. Environmental risk factors in Parkinson's disease. Mov Disord. 1999;14:928-39.

35. Zarzon M, Capus L, Pellegrino A, et al. Familial \& environmental risk factors in Parkinson's disease; a case control study in north east Italy. Acta Neurol Scand. 2002;105(2):77-82.

36. Rajput AH, Offord KP, Beard CM, et al. Epidemiology of Parkinsonism. incidence, classification, and mortality. Ann Neurol. 1984;16(3):278-82.

37. Gorell JM, Johnson CC, Rybicki BA, et al. The risk of Parkinson's disease with exposure to pesticides, farming, well water and rural living. Neurology. 1998;50:1346-50.

38. Vieregge P, Maravic CV, Friedrich HJ. Life-style and dietary factors early and late in Parkinson's disease. Can J Neurol Sci. 1992;19:170-3

39. Baron JA. Cigarette smoking and Parkinson's disease. Neurology. 1986;36:1490-6.

40. Kirch DG, Alho AM, Wyatt RJ. Hypothesis: a nicotine-dopamine interaction linking smoking with Parkinson's disease and tardive dyskinesia. Cell Mol Neurobiol. 1988;8:285-91.

41. Tanner CM, Grabler P, Goetz CG. Occupation and the risk of Parkinson's disease: a case-control study in young-onset patients. Neurology. 1990;40:422.

42. Pattarini R, Smeyne RJ, Morgan JI. Temporal mRNA profiles of inflammatory mediators in the murine 1-methyl-4-phenyl1,2,3,6-tetrahydropyrimidine model of Parkinson's disease. Neuroscience. 2007;145(2):654-68. 